\title{
When Domestic Violence Causes Gallbladder Injuries: A Case Report of Gallbladder Perforation
}

\author{
Paul K Okeny,, ${ }^{1, *}$ and Geoffrey Ndikaboona ${ }^{1}$ \\ ${ }^{1}$ Department of Surgery, Gulu Regional Referral and Teaching Hospital, Gulu, Uganda \\ "Corresponding author: Paul K Okeny, Department of Surgery, Gulu Regional Referral and Teaching Hospital, P. O. Box: 160, Gulu, Uganda. E-mail: okenykpaul@yahoo.ca
}

Received 2015 October 01; Accepted 2016 May 02.

\begin{abstract}
Traumatic injuries to the gallbladder are rare. This is attributed to its anatomical location and protection by the liver. Direct penetrating trauma is the commonest mechanism of injury. Here is the report of a 27-year-old otherwise healthy male who sustained gallbladder perforation following the penetration of abdominal injury in a domestic fight. A high index of suspicion is necessary for early diagnosis. He safely underwent an open cholecystectomy and his postoperative recovery was uneventful.
\end{abstract}

Keywords: Gallbladder Perforation, Domestic Violence, Open Cholecystectomy

\section{Introduction}

Traumatic gallbladder injuries are uncommon due to the anatomical location of the gallbladder. It is protected by the liver, intestines, omentum and rib cage $(1,2)$. More than $70 \%$ of gallbladder injuries are due to penetrating trauma and more than $90 \%$ are associated with other intraabdominal injuries (1). The slow development of peritonitis from sterile bile combined with a low index of suspicion lead to delayed diagnosis and intervention. Outcome mainly depends on the severity of the associated injuries. Here is the report on a case of gallbladder perforation sustained in a domestic violence.

\section{Case Presentation}

A 27-year-old subsistence farmer was referred from a district hospital to Gulu Regional Referral and Teaching Hospital in the evening of 3/03/2015. He complained of a three days history of severe generalized constant abdominal pain associated with fever, distension, absolute constipation and difficulty in breathing. He denied history of vomiting.

Three days earlier, he had been stabbed in the epigastrium by his own brother as he tried to stop a domestic fight between the brother and wife. He described the instrument as a $15 \mathrm{~cm}$ kitchen knife. He had lost approximately $50 \mathrm{~mL}$ of blood before being rushed to the district hospital where surgical toilet and suturing was done. Reason for referral was worsening abdominal symptoms.

On examination, his vital signs were as follows: temperature $37.5^{\circ} \mathrm{C}$, respiratory rate 35 breaths/minute, heart pulse rate $125 \mathrm{bpm}$ and blood pressure $80 / 50 \mathrm{mmHg}$. The abdomen was moderately distended but moving with respiration, had a $3 \mathrm{~cm}$ stitched laceration in the epigastrium about $1 \mathrm{~cm}$ to the right of the midline. There was percussion tenderness and guarding. Bowel sounds were reduced. Rectal exam was not done. His hemoglobin level was $12 \mathrm{~g} / \mathrm{dL}$ with a mean corpuscular volume (MCV) of $82 \mathrm{fL}$ (normal range 86 -110). Other cell lines were normal. Ultrasound showed massive intraabdominal fluid with the deepest pool at $5.7 \mathrm{~cm}$. Other organs were normal.

After three hours of crystalloid resuscitation, his vitals had improved to blood pressure-130/70 $\mathrm{mmHg}$, respiratory rate 26 breaths/minute, heart pulse rate $110 \mathrm{bpm}$ and oxygen saturation 95\% (on room air). A decision was then made to operate him in the following morning.

At laparotomy, one liter of free intraperitoneal bile was drained; a sealed grade II liver injury (left lobe) and a $4 \times 2$ $\mathrm{cm}$ perforation at the body of the gallbladder were found. The hepatic, cystic and common bile ducts were all intact. A fundus-first approach cholecystectomy was performed and peritoneal cavity irrigated with $4 \mathrm{~L}$ of warm saline. No drain was left in the abdomen. He did well postoperatively and was discharged on the 6th postoperative day. A thirtyday follow-up was uneventful.

\section{Discussion}

Gallbladder injuries are very rare $(1,2)$ and more than $70 \%$ of the time are due to penetrating trauma (1). In blunt abdominal trauma, gallbladder injuries account for only $2 \%$ of intraabdominal injuries (3). It was the first ever report of gallbladder perforation in the hospital.

Injuries to the gallbladder are rare due to its anatomical location. It is protected by the liver, intestines, omen- 
tum and rib cage. The spectrum of injuries includes contusion, laceration, perforation and avulsion (2). Torsion of the gallbladder though rare, can also occur (4). The current case patient had a $4 \times 2 \mathrm{~cm}$ perforation of the gallbladder secondary to a stab wound.

Isolated gallbladder injury is very rare. In a retrospective review of gallbladder injury patterns, operative treatment and outcome over a thirteen year period, only $2 \%$ of the injuries were isolated and the commonest associated organ injury was the liver. Only $7 \%$ had extra hepatic biliary duct injury. In the series, $49 \%$ of the patients with associated injuries had hemodynamic instability (1). Similarly, the current case patient with associated grade II liver injury presented a blood pressure of $80 / 50 \mathrm{mmHg}$ before resuscitation. However, isolated gallbladder injuries are reported in the literature (4-8).

The underlying mechanism of injury is a shearing acceleration-deceleration force or direct penetrating injury as is the current case report. A distended thin walled gallbladder is prone to injury. This distension could be due to prolonged starvation or increased tone of the sphincter of Oddi secondary to alcohol ingestion $(3,5,6)$. Alcohol stimulates gastrin and secretin release which in turn increase bile flow in the setting of a highly toned Sphincter of Oddi. There was no history of alcohol ingestion or prolonged starvation in the patient. The injury can only be attributed to the stab using a kitchen knife.

Time from injury to presentation may be delayed from about three to seven days (9) or even weeks (5). This occurs in traumatic ruptures in which the bile is sterile. However when they do present, almost all patients will have signs and symptoms of an acute abdomen (1). Similarly, the patient presented an acute abdomen three days after injury.

Computed tomography is the most reliable technique to diagnose gallbladder injuries (10). This is not found in many African centers. Clinicians should therefore have a high index of suspicion. In the review by Ball et al. (1), preoperative diagnosis of gall bladder injury was only possible in $16 \%$ of patients while focused assessment with sonography for trauma (FAST) was positive in $88 \%$ of them. An abdominal ultrasound scan was done for the patient, which revealed free intraperitoneal fluid. It was not possible to make a preoperative diagnosis of gallbladder perforation.

Treatment of traumatic gallbladder perforation may involve expectant observation, drainage, cholecystography or cholecystectomy (2). In gall bladder contusion/hematoma and absence of peritonitis, non operative management was successful by Wang et al. (7). Ninety three percent of patients reviewed by Ball et al. (1) underwent open cholecystectomy. The patient had open retrograde cholecystectomy due to inflammation and bile stain- ing at the Calot triangle (8). A laparoscopic approach is possible in other centers (11). In patients with very friable gallbladders, partial cholecystectomy is safe (12). Outcome depends on severity of associated injuries. The patient was discharged on the 6th postoperative day and a thirtyday follow-up was uneventful. This could probably be because he had only one associated injury, which had even healed/sealed by the time of the emergency laparotomy.

\subsection{Conclusion}

Traumatic gallbladder perforation is rare and a case associated with domestic violence was not reported previously. A high index of suspicion is necessary since percutaneous intra-abdominal bile aspirate may be due to duodenal/upper gastrointestinal tract injury. In resource limited settings, open cholecystectomy remains a safe and effective treatment option.

\section{Acknowledgments}

Authors acknowledge the contribution of the staff in the surgical ward towards the successful management of this patient.

\section{Footnotes}

Authors' Contribution: Geoffrey Ndikaboona did the initial clerking of the patient. Paul K Okeny performed the surgery and wrote the first draft of the manuscript. Both authors read and approved the final version of the manuscript.

Funding/Support: This work received no external funding.

\section{References}

1. Ball CG, Dixon E, Kirkpatrick AW, Sutherland FR, Laupland KB, Feliciano DV. A decade of experience with injuries to the gallbladder. $J$ Trauma Manag Outcomes. 2010;4:3. doi:10.1186/1752-2897-4-3. [PubMed: 20398307].

2. Zellweger R, Navsaria PH, Hess F, Omoshoro-Jones J, Kahn D, Nicol AJ. Gall bladder injuries as part of the spectrum of civilian abdominal trauma in South Africa. ANZ J Surg. 2005;75(7):559-61. doi: 10.1111/j.1445-2197.2005.03430.x. [PubMed:15972047].

3. Soderstrom CA, Maekawa K, DuPriest RWJ, Cowley RA. Gallbladder injuries resulting from blunt abdominal trauma: an experience and review. Ann Surg. 1981;193(1):60-6. [PubMed: 7006529].

4. Gupta V, Singh V, Sewkani A, Purohit D, Varshney R, Varshney S. Torsion of gall bladder, a rare entity: a case report and review article. Cases J. 2009;2:193. doi: 10.1186/1757-1626-2-193. [PubMed: 20062762].

5. Gali BM, Ali N, Bakari AA, Suleiman IE. Isolated gallbladder rupture following blunt abdominal trauma. Niger J Clin Pract. 2013;16(3):398400. doi: 10.4103/1119-3077.113474. [PubMed: 23771471].

6. Cheng YC, Yen PC, Tsai IT. Isolated Gallbladder Injury Due to Blunt Abdominal Trauma: A Case Report. E-Da Med J. 2014:35-7. 
7. Wang IT, Tsai MT, Huang CY, Tsai KC, Wu SH, Lien WC, et al. Isolated gallbladder hematoma after a blunt abdominal trauma: case report. Crit Ultrasound J. 2015;7(Suppl 1):A27. doi: 10.1186/2036-7902-7-S1-A27. [PubMed: PMC4401087].

8. Cheddie S, Manneh CG, Naidoo NM. Isolated gallbladder perforation following blunt abdominal trauma. S Afr J Surg. 2014;52(4):118. doi: 10.7196/sajs.2111.

9. Sharma O. Blunt gallbladder injuries: presentation of twenty-two cases with review of the literature. J Trauma. 1995;39(3):576-80. [PubMed: 7473927].

10. Wittenberg A, Minotti AJ. CT diagnosis of traumatic gallbladder in- jury. AJR Am J Roentgenol. 2005;185(6):1573-4. doi: 10.2214/AJR.04.1637. [PubMed: 16304015].

11. Kohler R, Millin R, Bonner B, Louw A. Laparoscopic treatment of an isolated gallbladder rupture following blunt abdominal trauma in a schoolboy rugby player. Br J Sports Med. 2002;36(5):378-9. [PubMed: 12351339].

12. Bainbridge J, Shaaban H, Kenefick N, Armstrong CP. Delayed presentation of an isolated gallbladder rupture following blunt abdominal trauma: a case report. J Med Case Rep. 2007;1:52. doi: 10.1186/1752-19471-52. [PubMed: 17634139]. 